\title{
A systematic review of work accommodations for people with mental disorders
}

\author{
Nayab Zafar ${ }^{\mathrm{a}, *}$, Martin Rotenberg ${ }^{\mathrm{b}}$ and Abraham Rudnick ${ }^{\mathrm{c}}$ \\ ${ }^{a}$ Previously: McMaster University, Hamilton, Ontario, Canada \\ ${ }^{\mathrm{b}}$ Department of Psychiatry, University of Toronto, Toronto, Ontario, Canada \\ ${ }^{\mathrm{c}}$ Dalhousie University, Halifax, Nova Scotia, Canada
}

Received 24 May 2018

Accepted 8 December 2018

\begin{abstract}
.
BACKGROUND: Work accommodations are adjustments made in the work place or to policies surrounding employment to accommodate an individual with a mental disorder to be successful in completing work related tasks.

OBJECTIVE: The purpose of this systematic review is to identify work accommodations that are available and that are provided to individuals with mental disorders. In addition, associated cost-effectiveness and cost-benefits of these accommodations are examined.

METHODS: Studies published between 1990-2016 from four databases were reviewed. From these databases, studies that specified accommodations that were available/provided and/or addressed cost-effectiveness or cost-benefit analysis of work accommodations were included.

RESULTS: Of the 1362 eligible studies, only 15 were included. Work accommodations that were provided to individuals assisted in mitigating limitations in the work place and improved length of job tenure, as well as reduced the severity of certain mental disorders. The costs associated with these accommodations were found to be minimal and had positive economic benefits for employers.

CONCLUSION: Work accommodations help individuals with mental disorders meet employment expectations with minimal cost.
\end{abstract}

Keywords: Accommodation, employment, mental disorder, psychiatric disability, work

\section{Introduction}

A mental disorder may affect various aspects of an individual's life, and may hinder the capacity to maintain self-efficacy by creating barriers to achieve goals, perform to societal expectations, and engage in adaptive coping due to functional limitations [1]. This may impede individuals with common mental disorders (e.g., major depressive disorder,

\footnotetext{
*Address for correspondence: Nayab Zafar, BSc. E-mail: z.nayab@hotmail.com.
}

anxiety disorders) and severe persistent mental disorders (e.g., schizophrenia, schizoaffective disorders) from maintaining long-term competitive employment. Individuals with psychiatric disabilities are more likely to be unemployed [2]. This is further compounded by stigmatization that individuals with a psychiatric disability experience, resulting in further social and economic marginalization [2]. Poor employment outcomes in individuals with a psychiatric disability have major economic implications and result in a loss of approximately $0.3 \%$ to $0.8 \%$ in national earnings [3]. 
Individuals with a mental disorder may experience a wide variety of functional barriers or limitations to meet employment expectations and tasks. Some of these limitations may include impairments in attention, executive function, and communication [4]. Work accommodations are modifications to either the physical work space or procedures and policies that enable individuals with disabilities to be successful in any working environment (e.g., office, home) [5]. In comparison to a physical disability where often a structural modification may be needed (e.g., physical work space modifications), individuals with a psychiatric disability may instead require organizational modifications (e.g., scheduling flexibility, job description modifications) [5]. Individuals with a mental disorder experience a variety of functional limitations that may be similar to those associated with physical disabilities (e.g., psychomotor slowing in depression). Therefore, it is possible that positive outcomes seen in work accommodations for individuals with physical disabilities can be translated to individuals with a psychiatric disability [6].

Many countries have legislation that protects the rights of individuals with disabilities in work places and prohibits discrimination - which includes discrimination based on physical or psychiatric disability [7]. Such legislation requires employers to provide accommodations to employees and may include a variety of adjustments such as changes in working hours or environmental modifications [8]. Despite legislation, employers may be reluctant in providing these accommodations due to limited understanding of such modifications, feasibility concerns and legal uncertainty. Additionally, the fear of further stigmatization from employers may reduce disclosure of disability and further result in a lack of support and accommodations, perpetuating lack of employment [9].

There has been limited research conducted regarding the categorization of employee and employerlevel interventions, which include accommodations that can lead to positive employment outcomes [10]. A scoping review on this topic by McDowell and Fossey (2015) [11], determined the size and scope of the available literature on the matter. Further important questions have yet to be investigated as there continues to be a great deal of fragmentation in the characterization of how work accommodations for individuals with psychiatric disabilities are described and the associated outcomes of their implementation. There is little understanding surrounding the frequency with which these accommodations are implemented and utilized. Increasing knowledge and understanding of work accommodations is important as individuals with psychiatric disabilities experience poor employment outcomes.

The aim of this systematic review is to addresses the following questions:

i. What work accommodations are available to address mental disorder-related impairments?

ii What work accommodations are provided to address mental disorder-related impairments?

iii. What are the impacts of work accommodations on employment outcomes of people with a mental disorder?

iv. What are direct and indirect costs associated with work accommodations for individuals with mental disorder-related impairments and their associated cost-effectiveness and cost-benefit?

We hypothesize that work accommodations that are made available and that are provided to address mental disorder related impairments will reduce limitations faced by these individuals. By providing accommodations, there will be an increase in the number of hours worked by the employee, longer job tenure, and ultimately benefit the employee with an increased income, as well as a decrease in overall costs to employers.

\section{Methods}

This systematic review utilized a standard and consistent methodology to selectively screen and analyze current literature and data to arrive at a conclusion [12]. The literature was screened to identify relevant articles - as defined by the inclusion criteria outlined in Table 1- that provided current information on work accommodations and their respective outcomes. Searches were conducted via PsychINFO, MEDLINE, EMBASE, and CINAHL to find relevant articles within the span of 26 years from 1990 to 2016. The search terms and strategy used in the databases are outlined in Table 2. In addition to keywords, subject headings were also included in the database search. Subject headings included: mental disorders or psychiatric disability or mental health and job accommodation when utilizable with the relevant database.

For this review, work accommodations are defined as modifications within any working environment 
Table 1

Inclusion/Exclusion Criteria

\begin{tabular}{ll}
\hline Inclusion Criteria & Exclusion Criteria \\
\hline Original empirical studies: & $\bullet$ Opinion pieces \\
- qualitative, quantitative, mixed-methods 1990-2016 & $\bullet$ Case reports and studies \\
- Studies specifying accommodations available/provided and/or & $\bullet$ Physical/Intellectual Disabilities \\
$\begin{array}{l}\text { cost-effectiveness and cost-benefits of work accommodations } \\
\text { - Employment outcomes discussed }\end{array}$ & $\bullet$ Studies referring to employment programs/interventions without \\
- English language articles & identifying specific work accommodations \\
\hline
\end{tabular}

Table 2

Search Terms and Keywords

\begin{tabular}{|c|c|c|c|c|}
\hline & PsychINFO & MEDLINE & EMBASE & CINAHL \\
\hline \multirow{4}{*}{$\begin{array}{l}\text { Subject Headings } \\
\text { Specific to } \\
\text { Databases }\end{array}$} & \multirow{4}{*}{$\begin{array}{l}\text { Mental Disorders } \\
\text { (explode) }\end{array}$} & \multirow{4}{*}{$\begin{array}{l}\text { Mental Disorders } \\
\text { (explode) }\end{array}$} & \multirow{4}{*}{$\begin{array}{l}\text { Mental Disorders } \\
\text { (explode) }\end{array}$} & Mental Disabilit*(explode) \\
\hline & & & & $\begin{array}{l}\text { Psychiatric Disabilit* } \\
\text { (explode) }\end{array}$ \\
\hline & & & & Mental Health (explode) \\
\hline & & & & $\begin{array}{l}\text { Job Accommodation* } \\
\text { (explode) }\end{array}$ \\
\hline \multirow[t]{2}{*}{$\begin{array}{l}\text { Keywords Used } \\
\text { in All Databases }\end{array}$} & \multicolumn{4}{|c|}{$\begin{array}{l}\text { Mental disability*or mental illness*or mental disorder*or mental health or mental health disorder } \\
{ }^{*} \text { or psychiatric disabilit*or mental health condition*or schizophrenia or anxiety*or bipolar* } \\
\text { or depression*, personality disorder* }\end{array}$} \\
\hline & \multicolumn{4}{|c|}{$\begin{array}{l}\text { Employment Support*or job modification* or job accommodation or job adjustment or work } \\
\text { accommodation*or work adjustment*or work modification* }\end{array}$} \\
\hline
\end{tabular}

(e.g., office, home) that relate to employment outcomes. These may include social (e.g., communication, presentations) and organizational (e.g., work duties, scheduling) adjustments. Cost-effectiveness and cost-benefits are categorized by both direct and indirect costs, with cost-benefit being the monetary value associated with work accommodations and cost-effectiveness being the overall financial analysis of these accommodations on the employers, employees, and the society as a whole. Direct costs are defined as costs associated with the implementation of the accommodation (e.g., startup cost) and indirect costs are defined as the downstream and overhead costs associated with the accommodation (e.g., extra supervisory hours, maintenance fees) [13].

The first author conducted the search through multiple databases. The first and second authors screened the article in terms of the inclusion/exclusion criteria based on the title and abstracts. Articles that outlined the classification, frequency and cost-benefits of work accommodations for individuals with a mental disorder were included. In order to elucidate the direct and indirect costs associated with work accommodations, the keywords "cost" and "effectiveness" were included in a preliminary search; however due to lack of results, these specific terms were not used in the final search. To ensure that no relevant studies were missed within the literature both backward and forwards searches were conducted on all included studies.

\section{Results}

Of the 1362 eligible studies, 59 studies were selected for full review. Figure 1 outlines the review process. Of the 59 studies reviewed, 14 were included. One study was included from the forward and backward search of included studies after fulltext review. This resulted in a total of 15 studies included in the final review. The primary reasons for the exclusions of studies was secondary to not being an empirical study, or not discussing specific work accommodations and related outcomes.

The majority of studies included $(n=9)$ were conducted in the USA. Three studies were conducted in Canada, 1 was conducted in the UK, and 1 was conducted in Australia. In addition, there was 1 international collaborative study from Italy, Australia and Canada. The majority of the studies were quantitative $(n=12)$. There were no experimental studies. The studies mainly employed the use of surveys, self-administered questionnaires, and structured/semi-structured interviews to gather data. 


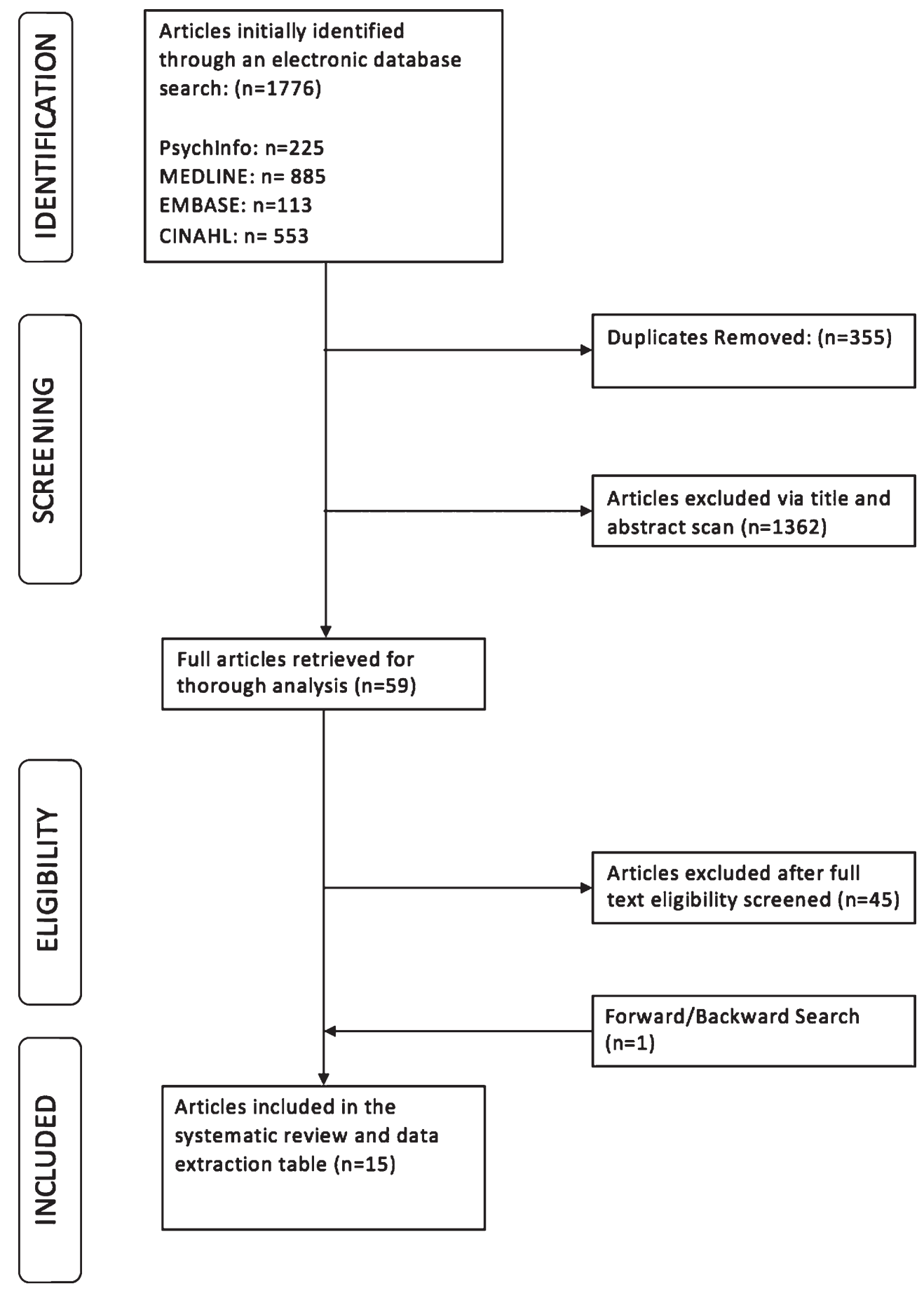

Fig. 1. PRISMA Flow diagram.

Eleven studies discussed various types of accommodations available and the specific accommodations that were provided, as well as effects on employment outcomes. Eleven studies included participants with a severe and persistent mental disorder, 3 with common mental disorders, and 1 with bipolar disorders. Four studies discussed both the direct and indirect costs associated with work accommodations. 


\subsection{Classification of accommodations to address mental disorder associated impairments}

Table 3 classifies accommodation by 4 major categories. Of the 15 papers included, 11 discussed specific accommodations [5, 14-23]. All the accommodations from the review were consolidated and associated with a functional limitation - which is an operational definition of impairment. The classification system was adapted and expanded from the classification utilized in the supported employment context by MacDonald and colleagues (2003) to include accommodations and limitations outside and beyond supported employment. Functional limitations have been classified as being either [19]:
1) physical,

2) emotional,

3) cognitive or,

4) social.

\subsection{Accommodations provided}

Seven studies [5, 17-19, 22-24].studied the provision of work accommodations. There were no studies which differentiated between work accommodation that are available or offered to individuals if needed, versus those that are actually provided or accessed.

In a study by Wang and Patten (2011), approximately a third $(30.5 \%)$ of individuals reported receiving the entire extent of their required modifications, while $16.8 \%$ received nil. Individuals with a

Table 3

Classification of accommodations

\begin{tabular}{|c|c|c|}
\hline Category of Accommodations & Specific Accommodations & Functional Limitation \\
\hline \multirow[t]{14}{*}{ Communication Facilitation Accommodations } & Job Coach & Social \\
\hline & Permitting Calls to Job Coaches & Social \\
\hline & Positive Calls to Job Coaches & Social \\
\hline & Positive feedback used by supervisor & Social \\
\hline & Task planning and setting priorities & Cognitive/Emotional \\
\hline & $\begin{array}{l}\text { Use of method of providing feedback and instructions } \\
\text { (e.g., email, written instructions) }\end{array}$ & Social/Cognitive \\
\hline & Provisions of co-worker friend & Social \\
\hline & Added supervision & Social/Cognitive \\
\hline & Limiting changes in supervision/staff & Social \\
\hline & Orientation for supervisors to provide accommodations & All \\
\hline & Weekly meetings with supervisor & Cognitive/Social \\
\hline & Extended job training & Cognitive \\
\hline & Orienting Co-workers & Social \\
\hline & Employee Assistance Program Service & All \\
\hline \multirow[t]{7}{*}{ Scheduling Flexibility Accommodations } & Switch to part-time hours & Emotional \\
\hline & Time off for medical appointments & Emotional/Physical \\
\hline & Flexible work schedules & Emotional/Cognitive \\
\hline & Availability of time-off without pay & Emotional \\
\hline & More frequent Breaks & Emotional \\
\hline & Extra time to complete tasks & Cognitive \\
\hline & Slowing pace of tasks & Cognitive \\
\hline \multirow[t]{7}{*}{ Job Description Modification Accommodation } & Gradual task introduction & Cognitive/Emotional \\
\hline & Minimizing changes to job description over time & Cognitive \\
\hline & Job sharing/trading & Cognitive \\
\hline & Work from home & Emotional/Physical \\
\hline & Postponing tasks & Cognitive/Emotional \\
\hline & Breaking down tasks into smaller tasks & Cognitive/Emotional \\
\hline & Change to a different position & Cognitive/Emotional \\
\hline \multirow[t]{7}{*}{ Physical Space Accommodation } & Access to water in work place & Emotional/Physical \\
\hline & Access to rest area & Emotional/Physical \\
\hline & Access to private area & Emotional \\
\hline & Changes in spatial arrangements & Emotional/Cognitive \\
\hline & Lower noise levels & Emotional/Cognitive \\
\hline & Changing light arrangements & Emotional/Cognitive \\
\hline & Access to refrigeration for medication & Emotional \\
\hline Other & Transportation & Physical \\
\hline
\end{tabular}




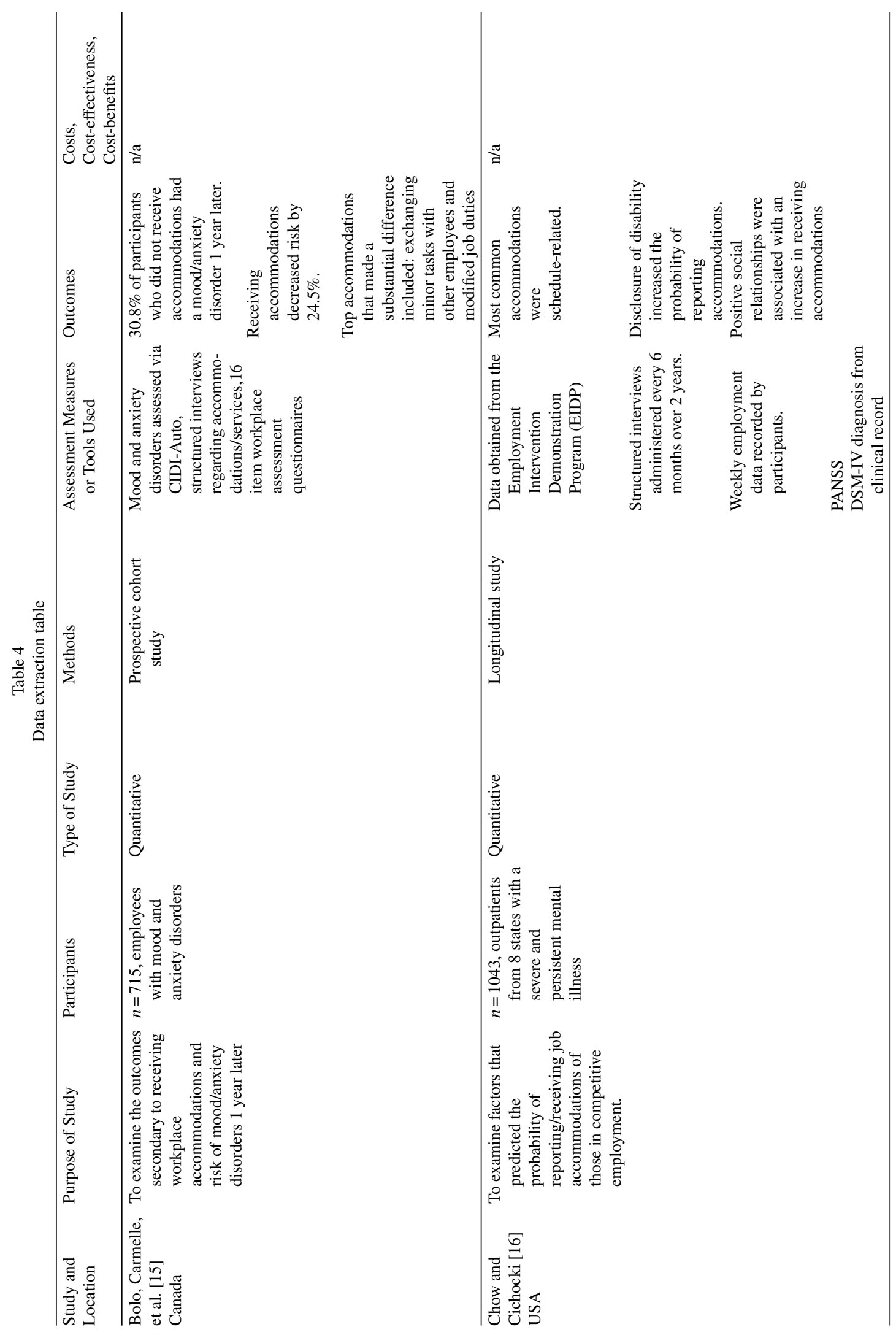




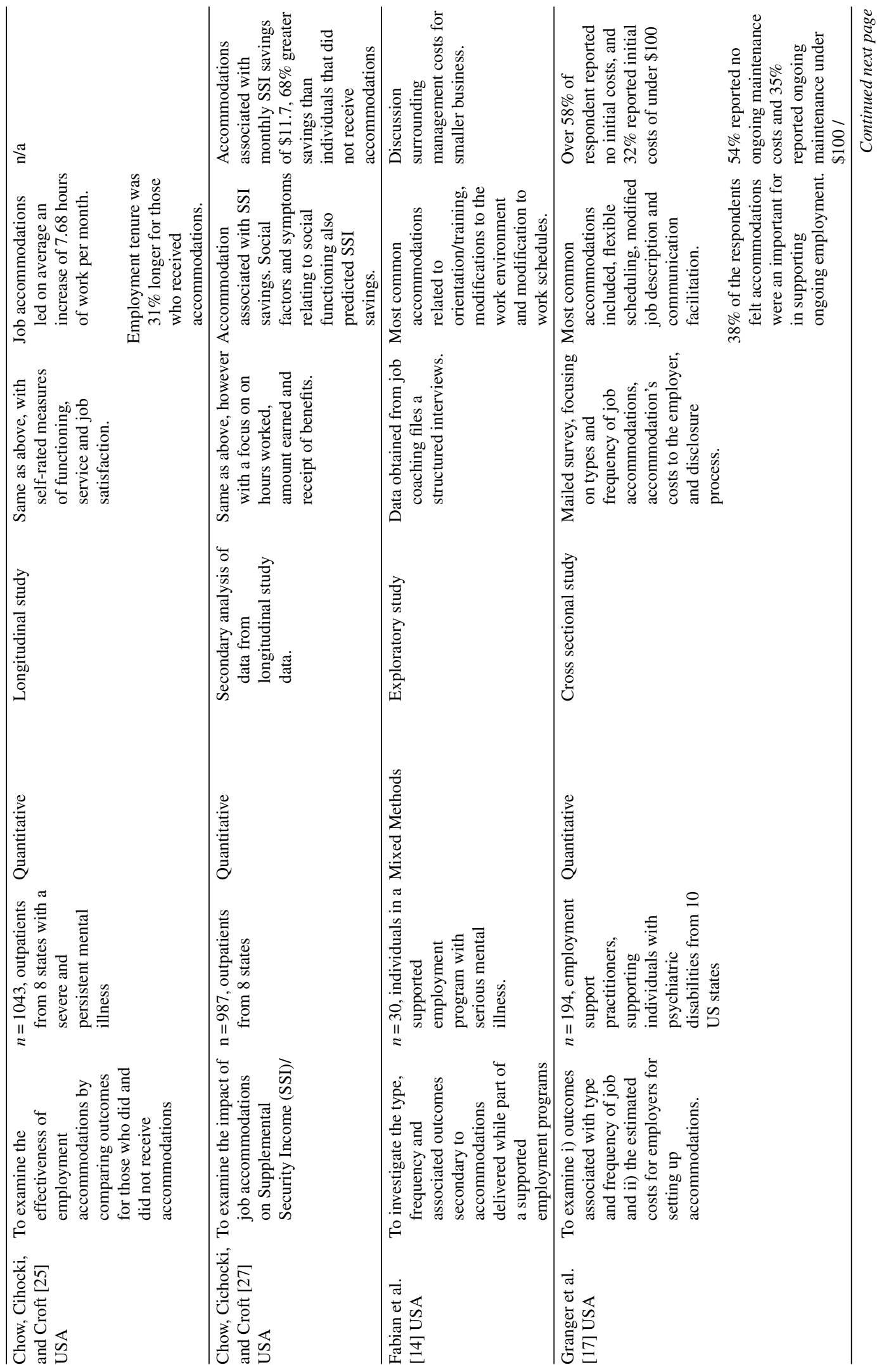




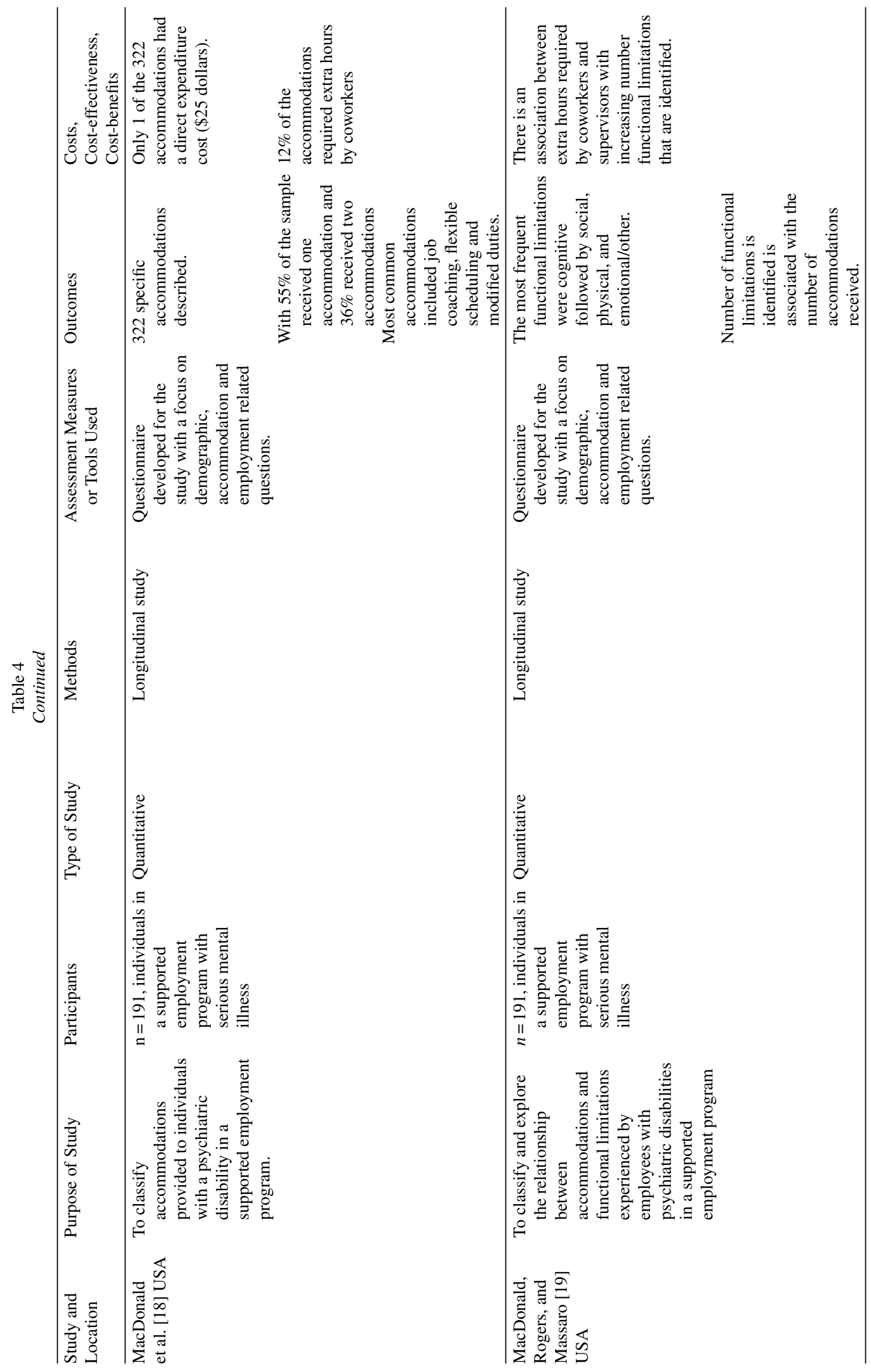




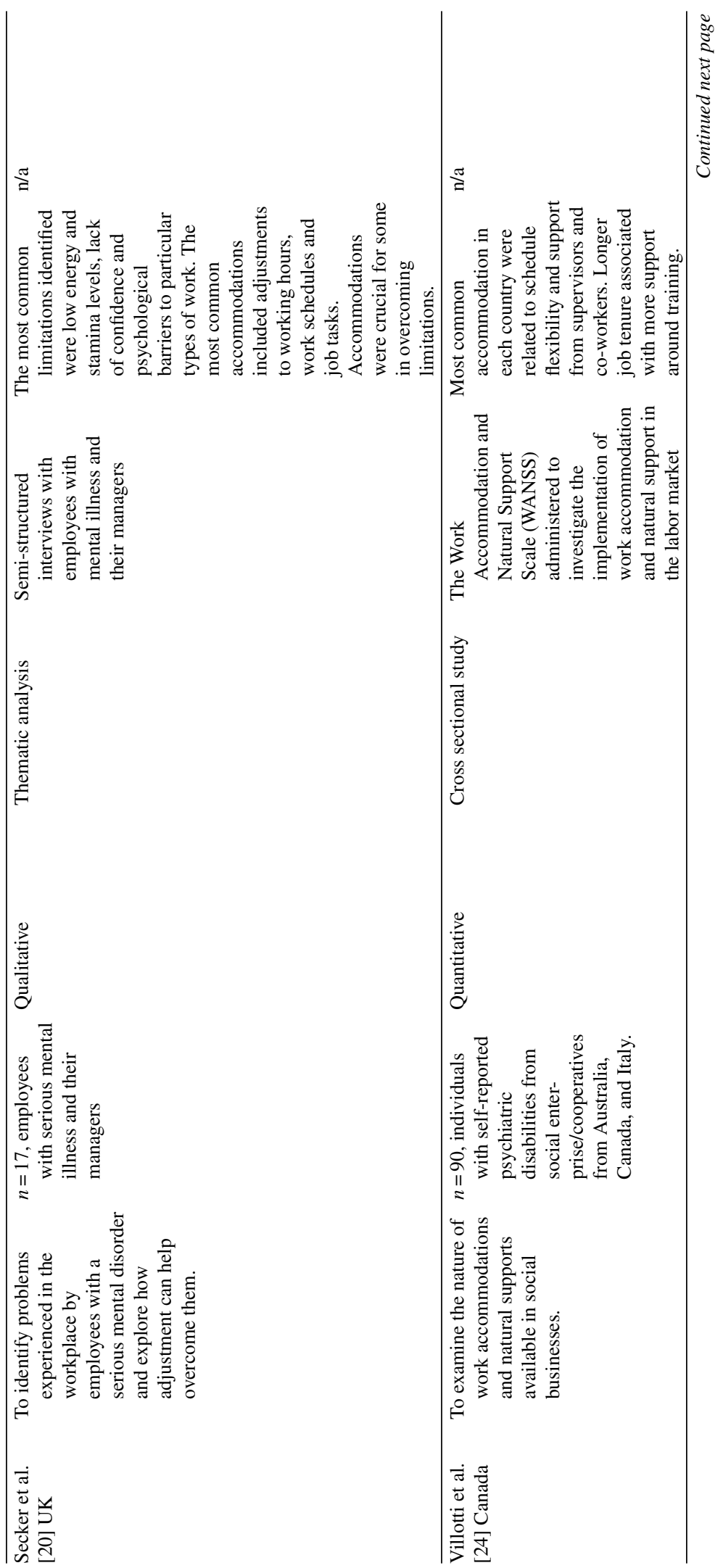




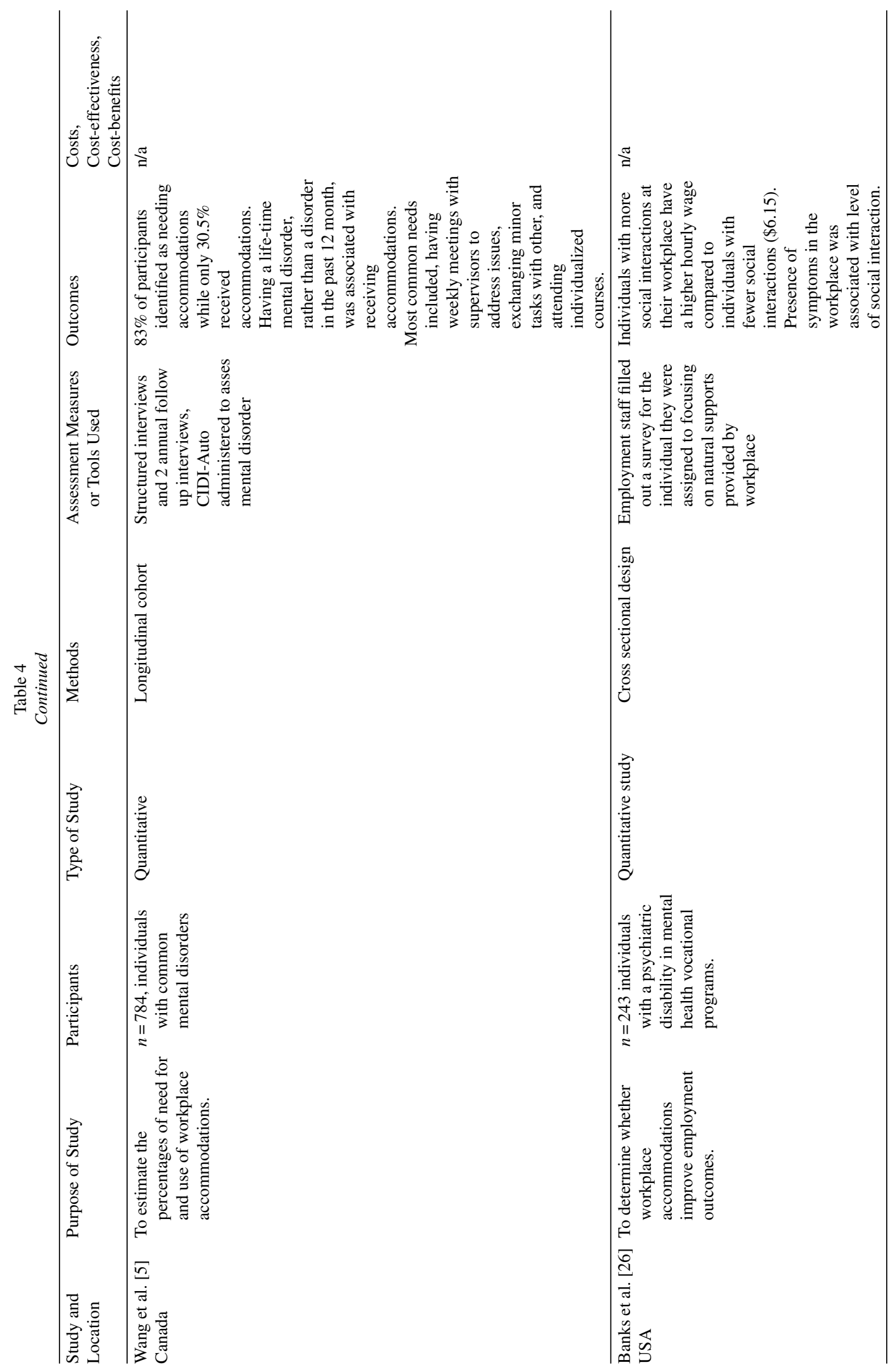




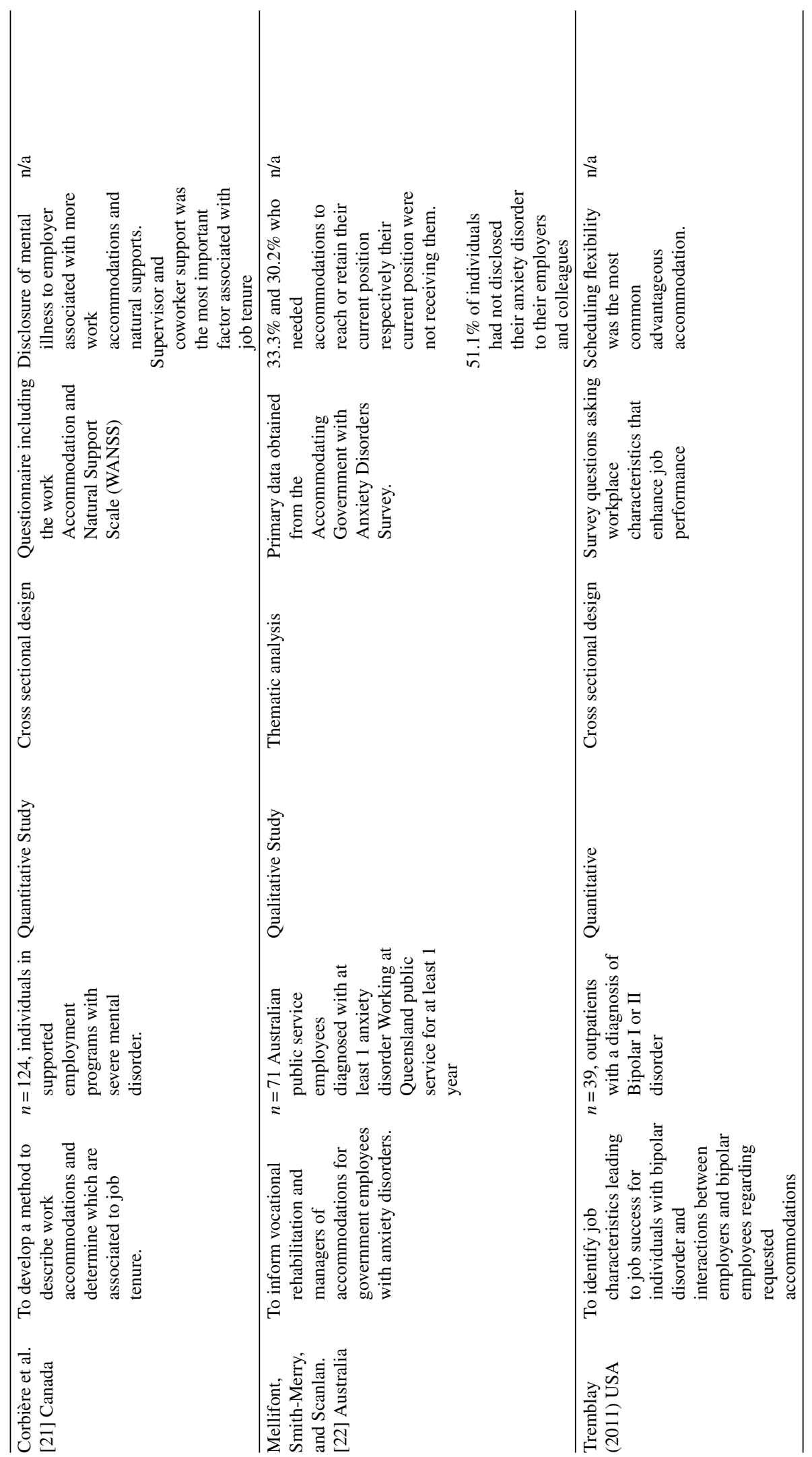


disorder classified as a lifetime disorder were more likely to receive accommodations in comparison to those with a 12-month disorder [5]. In addition, 3 most common accommodations for employees with a mood and/or anxiety disorders included: 1) having weekly meetings between supervisors and employees to address issues in the work place, 2) exchanging minor tasks with other employees and 3) attending courses that are individualized. For these accommodations, there was no distinction between individuals with or without a 12-month mental disorder.

The most common accommodations across 4 studies included [5, 17, 22, 24]: communication facilitation accommodations (CFA) and scheduling flexibility (SF). Of the various CFA's available, Granger and colleagues (1997) found that job coaching was the most frequently used [17]. With regards to flexible scheduling, switching from fulltime to part-time work hours was the most commonly implemented accommodation within this category. However, $43 \%$ of respondents stated that scheduling was the most challenging accommodation to be arranged and negotiated with their employers and coworkers [17]. The least common from within this category included the availability of time off without pay, use of vacation or personal time for medical needs, and frequent breaks. These results were consistent with the international study by Villoti and colleagues (2007) which also found that the most common accommodations provided in each country were communication facilitation and scheduling flexibility [24]. Three other studies [18, 19, 23] had similar results, however, the specific accommodations that they found to be most common within the categories of CFA and SF varied.

Within the category of job description modification, the gradual introduction of tasks was the most common accommodation, while exchanging tasks with other employees was the least [17]. Physical space accommodations (PSA) were reported to be the least frequent accommodation provided [5, 17-19, 24]. Within this category, access to water and rest area were the most common accommodations while changes in light arrangements and modification in noise levels were the least [17].

With respect to functional limitations, MacDonald and colleagues (2003) identified the specific mean number of accommodations required to address a functional limitation. On average, a single functional limitation required 1.19 accommodations and received on average 1.73 additional support hours within a supported employment setting [19]. With greater number of limitations, the corresponding number of accommodations provided and additional support hours increased as well. Individuals with cognitive or social limitations were more likely to receive accommodations involving human assistance (62\% \& $92 \%$ respectively) and those with physical limitations were more likely to receive flexible scheduling $(65 \%)$ [19]. Furthermore, supervisors with greater experience working with individuals with a mental disorder were more likely to offer scheduling flexibility [19].

\subsection{Impact of work accommodations}

Nine studies [14-16, 20-22, 24-26] examined outcomes associated with work accommodations. There is a positive correlation between accommodation and the length of employment tenure [25]. Fabian and colleagues (1993) identified that individuals who received greater than 5 work accommodations experienced on average a 24-month job tenure, whereas in contrast, individuals with less than 5 accommodations experienced half the length of job tenure at 12 months [14].

Chow and colleagues (2014) reported a similar trend, with mean job tenure being $31 \%$ longer when accommodations were provided, which translated to 7 months of additional employment [25]. Receiving work accommodations related to scheduling flexibility and further training has the greatest impact on the length of tenure [24]. Not disclosing a mental disorder can limit accessing accommodations and reduce job tenure [16]. Employees who had not disclosed their condition to employers, observed a reduced job tenure of 3.6 months [14]. These results were also reflected in a study by Corbière and colleagues, where job tenure was positively correlated with disclosure [21].

In addition to job tenure, wages were also affected by an individual's mental disorder. Banks and colleagues (2001) found that individuals with common mental disorders have greater social interaction in the work environment, when compared to individuals with severe and persistent mental illness, and was on average associated with a higher hourly wage. The level of social interaction in the work environment may be directly related to the symptoms of specific conditions [26].

Work accommodations can also influence mental health and wellbeing. Bolo and colleagues (2013) found that individuals who received adequate levels of work accommodations were less likely to have 
a mood and/or anxiety disorder after one year, than compared to those individuals who received insufficient accommodations [15].

The majority of studies described positive outcomes associated with accommodations. There is very limited mention of potential negative outcomes associated with accommodations in the literature. One exception is a study by Secker and colleagues (2003) which did discuss negative impacts of accommodations. In that study some participants felt "overprotected" or "patronized", and felt that some accommodations were "inappropriate". In addition, some participants reported feeling insufficiently challenged due to the limited tasks, which resulted in a loss of motivation to attend work [20].

\subsection{Direct and indirect costs associated with work accommodations}

Three studies evaluated costs associated with accommodations $[14,17,18]$, and 1 evaluated the potential savings to Supplemental Security Income (SSI) [27]. No specific study conducted a formal cost-benefit or cost-effectiveness analysis, however general costs and their associated outcomes were discussed.

Granger and colleagues (1997) described the findings of a national survey of job coaches and developers which included inquiries about both the initial (direct costs) and monthly maintenance costs (indirect costs) of work accommodations. Over half (58\%) of the respondents reported that there were zero initial startup costs, while $32 \%$ reported costs of less than $\$ 100$. Only 3\% of respondents reported initial costs of over $\$ 500$. Similarly, over half the respondents (54\%) reported zero monthly maintenance costs of accommodations as well as roughly a third (35\%) indicated costs totaling less than $\$ 100$. Only $1 \%$ of respondents reported monthly maintenance costs of over $\$ 500$.

A longitudinal, multi-site investigation conducted by MacDonald and colleagues (2002), investigated the direct and indirect costs of accommodations from four supported employment service providers. This study reported that the service providers only reported a single direct cost of $\$ 25$ for a job performance test, while over a third of accommodations included reallocation of supervisory hours.

A study conducted by Chow and colleagues (2014), elucidated the economic benefits of implementing work accommodations on broader Supplemental Security Income (SSI) expenditures. Results from this study concluded that working adults with accommodations were associated with a monthly SSI saving of $\$ 11.73$ which was $68 \%$ greater saving than those not receiving accommodations [27].

\section{Discussion}

This review systematically identified work accommodations that are available and provided to individuals with mental disorders. Furthermore, this review outlined both the outcomes and the associated costs of these accommodations. Overall, there are positive outcomes associated with work accommodations for individuals with mental disorder related impairments across diagnoses and employment contexts.

With regards to employment outcomes, our hypothesis - that work accommodations provided will address mental disorder by mitigating functional limitations - was supported, as various studies demonstrated a positive relationship between accommodations and length of job tenure, and reduced course of certain mental conditions such as anxiety and/or mood disorders [15]. Moreover, positive impacts of work accommodations on employment outcomes were demonstrated, as accommodations were shown to be associated with a longer job tenure between 7-24 months of when compared to individuals receiving no accommodations [14, 25]. Work accommodations assisted in facilitating a favorable work environment such as ensuring a manageable workload, flexibility in hours, and support from supervisors and coworkers. These accommodations contributed in reducing job-related stress which may be associated with the prevalence of some disorders such as depression and anxiety-related disorders [15]. Individuals who do not receive accommodations may experience disruptions in employment which may result in a decrease of social support, financial stress, and worsening of symptoms [15].

There is no "one size fits all" arrangement with respect to work accommodations, and not all accommodations may benefit all individuals in the same way. In this review, accommodations were categorized into the following categories: 1) Communication Facilitation 2) Flexible Scheduling 3) Job Description and 4) Physical Space and 5) Other. None of the studies included in this review provided a comprehensive list of all potential accommodations that may be provided to individuals with mental disorders, however two studies $[14,18]$ numerically identified 231 and 322 accommodations respectively, but did 
not provide a comprehensive list of what these were. Of the studies, which outlined specific accommodations, the most common accommodations were communication facilitation and scheduling flexibility related accommodations [5, 17, 22, 24], while physical modifications accommodations were the least common.

Despite their apparent benefits, findings from the studies demonstrated that work accommodations are not frequently implemented. This can be attributed to lack of exposure to and knowledge surrounding mental health issues. Employment supervisors with adequate mental health training, and previous experience working with employees with mental disorders, were more likely to offer accommodations [19]. Furthermore, there may be a lack of awareness among both employers and employees of the legislativelymandated right to reasonable work accommodations. The perceived adverse repercussions of disclosure of a mental disorder, may reduce the likelihood of accommodation [16]. Adequate education of the importance and rights to receive work accommodations is essential to improve the understanding of the legislations among supervisors and employees. Job coaches and vocational rehabilitation specialists can assist clients by providing education surrounding rights related to the disclosure of the mental disorder and the negotiation of obtaining reasonable accommodations under relevant legislation.

A barrier to implementation of work accommodations from the perspective of employers may include the perceived costs of implementing such accommodations. However, the studies which looked at costs associated with accommodations demonstrated minimal costs and lead to potential of downstream savings [27]. Work accommodations may have the potential to provide government savings in several hundred million dollars in SSI expenditure [28]. With respect to direct costs, they were minimal or otherwise nil [17]. Indirect costs were in the form of additional supervision or frequent breaks. Extra supervisory hours can potentially have a "hidden" cost associated with them and may become a significant expenditure for smaller companies [14]. Overall, the majority of direct and indirect costs associated with work accommodations are minimal, and have the potential to provide economic benefits for both employers and employees.

The limitations of specific studies included in the review mainly centered around their generalizability to the greater population. The included study samples were heterogeneous as (and participating) individu- als had diverse diagnoses across a wide variety of employment contexts. There was only a single study [19] that investigated the relationship between functional limitations and work accommodations. This limited the generalizability of overall findings. Additional limitations included the fact that many of the studies had small sample sizes and non-random samples. In addition, 8 studies relied on self-reporting which may have led to a reporting bias. There were no randomized controlled trial studies as the studies were predominantly observational studies. This limited the ability for discussion on causality. Furthermore, only English language studies, published between the years 1990- 2016, were eligible for inclusion, which may have further limited the data collected for this review.

\section{Conclusion}

Work accommodations facilitate environments where individuals with a mental disorder (or disorders) can meet employment expectations and perform required responsibilities. A wide variety of accommodations may be provided with generally positive outcomes and minimal cost across different work contexts, for individuals with a variety of diagnoses. For increased implementation of accommodations, further education surrounding relevant legislation (jurisdiction specific), the minimal costs associated with accommodation, potential economic benefits, and guidance on how to implement accommodations will be beneficial.

While studies have demonstrated positive employment outcomes for individuals with a mental disorder, further research is important to better understand challenges that may exist in accessing these interventions. Considering the heterogeneity in the sample from a diagnostic perspective, focusing on functional limitations which may occur across a wide range of diagnostic categories may be important. Further research looking at which accommodations specifically benefit individuals with certain limitations may be important for future interventions and education in the work place.

Challenges surrounding disclosure in the work environment and stigma play an important role obtaining accommodations within the work place. Future studies should examine the relation between stigma, disclosure and accommodation as this may be an important area for further education initiatives and interventions. In addition, further research is needed 
to formally and systematically examine the cost benefit and cost-effectiveness of work accommodations. Further high-quality evidence can assist in increasing implementation of accommodations by employers, tenure of employment and work satisfaction of people with mental disorders.

\section{Conflict of interest}

None to report.

\section{References}

[1] Rudnick A. What is a psychiatric disability? Health Care Analysis. 2014;22(2):105-13.

[2] Waghorn G, Saha S, Harvey C, Morgan VA, Waterreus A, Bush R, Castle D, Galletly C, Stain HJ, Neil AL, McGorry P. 'Earning and learning in those with psychotic disorders: The second Australian national survey of psychosis. Australian and New Zealand Journal of Psychiatry. 2012;46(8):774-85.

[3] Levinson D, Lakoma MD, Petukhova M, Schoenbaum M, Zaslavsky AM, Angermeyer M, Borges G, Bruffaerts R, De Girolamo G, De Graaf R, Gureje O. Associations of serious mental illness with earnings: Results from the WHO World Mental Health surveys. The British Journal of Psychiatry. 2010;197(2):114-21.

[4] Mancuso LL. Reasonable accommodation for workers with psychiatric disabilities. Psychosocial Rehabilitation Journal. 1990;14(2):3

[5] Wang J, Patten S, Currie S, Sareen J, Schmitz N. Perceived needs for and use of workplace accommodations by individuals with a depressive and/or anxiety disorder. Journal of Occupational and Environmental Medicine. 2011;53(11):1268-72.

[6] Unger D, Kregel J. Employers' knowledge and utilization of accommodations. Work. 2003;21(1):5-15.

[7] Lynk, M. The duty to accommodate in the canadian workplace: Leading principles and recent cases. Ontario Federation of Labour Sault Ste Marie. 2008.

[8] Rotenberg M, Zafar N, Akhtar N, Rudnick A. Addressing workplace accommodations for people with mental illness. Journal of Psychosocial Rehabilitation and Mental Health. 2016;3(2):117-8.

[9] Schartz HA, Schartz KM, Hendricks DJ, Blanck P. Workplace accommodations: Empirical study of current employees. Miss LJ. 2005;75:917.

[10] Krupa T. Interventions to improve employment outcomes for workers who experience mental illness. The Canadian Journal of Psychiatry. 2007;52(6):339-45.

[11] McDowell C, Fossey E. Workplace accommodations for people with mental illness: A scoping review. Journal of Occupational Rehabilitation. 2015;25(1):197-206.

[12] Buchanan D, Bryman A, editors. The SAGE handbook of organizational research methods. Sage Publications Ltd; 2009.

[13] Newcomer K, Hatry H, Wholey J. Handbook of Practical Evaluation. San Francisco: Wiley \& Sons Inc. 2015.
[14] Fabian ES, Waterworth A, Ripke B. Reasonable accommodations for workers with serious mental illness: Type, frequency, and associated outcomes. Psychosocial Rehabilitation Journal. 1993;17(2):163.

[15] Bolo C, Sareen J, Patten S, Schmitz N, Currie S, Wang J. Receiving workplace mental health accommodations and the outcome of mental disorders in employees with a depressive and/or anxiety disorder. Journal of Occupational and Environmental Medicine. 2013;55(11):1293-9.

[16] Chow CM, Cichocki B. Predictors of job accommodations for individuals with psychiatric disabilities. Rehabilitation Counseling Bulletin. 2016;59(3):172-84.

[17] Granger B, Baron R, Robinson S. Findings from a national survey of job coaches and job developers about job accommodations arranged between employers and people with psychiatric disabilities. Journal of Vocational Rehabilitation. 1997;9(3):235-51.

[18] MacDonald-Wilson KL, Rogers ES, Massaro JM, Lyass A, Crean T. An investigation of reasonable workplace accommodations for people with psychiatric disabilities: Quantitative findings from a multi-site study. Community Mental Health Journal. 2002;38(1):35-50.

[19] MacDonald-Wilson KL, Rogers ES, Massaro J. Identifying relationships between functional limitations, job accommodations, and demographic characteristics of persons with psychiatric disabilities. Journal of Vocational Rehabilitation. 2003;18(1):15-24.

[20] Secker J, Membrey H, Grove B, Seebohm P. The how and why of workplace adjustments: Contextualizing the evidence. Psychiatric Rehabilitation Journal. 2003;27(1):3.

[21] Corbière M, Villotti P, Lecomte T, Bond GR, Lesage A, Goldner EM. Work accommodations and natural supports for maintaining employment. Psychiatric Rehabilitation Journal. 2014;37(2):90.

[22] Mellifont D, Smith-Merry J, Scanlan JN. Disabling accommodation barriers: A study exploring how to better accommodate government employees with anxiety disorders. Work. 2016;55(3):549-64.

[23] Tremblay CH. Workplace accommodations and job success for persons with bipolar disorder. Work. 2011;40(4):479-87.

[24] Villotti P, Corbière M, Fossey E, Fraccaroli F, Lecomte T, Harvey C. Work accommodations and natural supports for employees with severe mental illness in social businesses: An international comparison. Community Mental Health Journal. 2016:1-7.

[25] Chow CM, Cichocki B, Croft B. The impact of job accommodations on employment outcomes among individuals with psychiatric disabilities. Psychiatric Services. 2014;65(9):1126-32.

[26] Banks B, Charleston S, Grossi T, Mank D. Workplace supports, job performance, and integration outcomes for people with psychiatric disabilities. Psychiatric Rehabilitation Journal. 2001;24(4):389.

[27] Chow CM, Croft B, Cichocki B. Evaluating the potential cost-savings of job accommodations among individuals with psychiatric disability. Journal of Vocational Rehabilitation. 2015;43(1):67-74.

[28] Drake RE, Skinner JS, Bond GR, Goldman HH. Social Security and mental illness: Reducing disability with supported employment. Health Affairs. 2009;28(3):761-70. 